\title{
MASS PRODUCTION OF HYDROGENATED ZnO NANORODS
}

\author{
${ }^{1}$ Yu Ying CHANG, 'Zdenek REMES, 2Julia MICOVA \\ ${ }^{1}$ Czech Academy of Sciences, Institute of Physics, Prague, Czech Republic, EU, \\ chang@fzu.cz, remes@fzu.cz \\ ${ }^{2}$ Slovak Academy of Sciences, Institute of Chemistry, Bratislava, Slovak Republic, EU, \\ chemiumi@savba.sk
}

https://doi.org/10.37904/nanocon.2019.8680

\begin{abstract}
We have developed an inexpensive and efficient technology of hydrothermal growth of $\mathrm{ZnO}$ nanorods from zinc nitrate hexahydrate $\left(\mathrm{Zn}\left(\mathrm{NO}_{3}\right)_{2} \cdot 6 \mathrm{H}_{2} \mathrm{O}\right)$, as a precursor and hexamethylenetetramine $(\mathrm{HMTA})\left(\mathrm{C}_{6} \mathrm{H}_{12} \mathrm{~N}_{4}\right)$, as a surfactant followed by plasma hydrogenation in a novel inductively coupled plasma (ICP) quartz reactor and equipped with the rotary sample holder to stir powder during plasma treatment. We have optimized the photoluminescence spectroscopy for measuring optical scattering samples with the high sensitivity, precise sample positioning and very low influence of the scattered excitation light. Here we present the latest results on the enhancement of the UV photoluminescence of the $\mathrm{ZnO}$ nanorods after plasma hydrogenation. The exciton-related photoluminescence has been significantly enhanced whereas the deep defect related yellow photoluminescence has been significantly decreased.
\end{abstract}

Keywords: Nanomaterials, $\mathrm{ZnO}$, photoluminescence, excitons, inductively coupled plasma, hydrogenation

\section{INTRODUCTION}

Zinc oxide is one of the most popular II-VI semiconductors, because of its low-cost, non-toxicity, wide band gap of $3.36 \mathrm{eV}$ and big exciton energy of $60 \mathrm{meV}$. Additionally, $\mathrm{ZnO}$ is a material with a great diversity of morphologies. Due to a high surface-to-volume ratio and related size effects, $\mathrm{ZnO}$ nanorods (NRs) are a perspective for energy conversion or sensing applications such as solar cells, light emitting diodes [1], high performance electrochemical capacitors [2], biosensors [3], gas sensors [4] or highly efficient scintillators [5]. The surface composition of the ZnO NRs drastically changes upon the exposure to hydrogen and oxygen plasma treatments affecting the defects creation processes [6]. The first-principles studies of the native point defects in $\mathrm{ZnO}$ have been reported previously [7]. However, the role of native defects in $\mathrm{ZnO}$ nanorods is still not fully understood [8]. The synthesis of ZnO NRs has been performed through complex methodologies, most of them starting with a seed layer followed by NRs growth. Nanopowders tend to form agglomerates due to different reasons that include electrostatic and Van der Waals forces or because they are interlaced by different geometry of the nanoparticles. Sonication is a powerful tool for the treatment of dispersing nanoparticles; it is easy to use, inexpensive and efficient. We have developed the technology of hydrothermal growth of $\mathrm{ZnO} N R s$ powder from zinc nitrate hexahydrate $\left(\mathrm{Zn}\left(\mathrm{NO}_{3}\right)_{2} \cdot 6 \mathrm{H}_{2} \mathrm{O}\right)$ and hexamethylenetetramine $(\mathrm{HMTA})\left(\mathrm{C}_{6} \mathrm{H}_{12} \mathrm{~N}_{4}\right)$ and shown that the surface composition drastically changes upon the exposure to plasma treatments [9-11].

\section{EXPERIMENTAL}

\subsection{Growth of $\mathrm{ZnO}$ nanorods}

Zinc nitrate hexahydrate p.a. $\left(\mathrm{Zn}\left(\mathrm{NO}_{3}\right)_{2} \cdot 6 \mathrm{H}_{2} \mathrm{O}\right)$ and hexamethylenetetramine $(\mathrm{HMTA})\left(\mathrm{C}_{6} \mathrm{H}_{12} \mathrm{~N}_{4}\right)$ p.a. was purchased from Slavus. Deionized water was purified with a So-Safe Water Technologies, having a conductivity $0.20 \mu \mathrm{S} \cdot \mathrm{cm}^{-1}\left(25^{\circ} \mathrm{C}\right)$. The chemicals were used in ambient conditions and without further 
purification. The reaction conditions were $25 \mathrm{mM}$ aqueous solutions $\mathrm{Zn}\left(\mathrm{NO}_{3}\right)_{2} \cdot 6 \mathrm{H}_{2} \mathrm{O}$ and HMTA at $90{ }^{\circ} \mathrm{C}$ for $3 \mathrm{~h}$. The precursor salt residue was removed from the sample by washing 3-times with deionized water followed by centrifugation at $18,000 \mathrm{rpm}$ (RCF: $23542 \mathrm{~g}$ ) for $20 \mathrm{~min}$. Finally, the ZnO NRs were dried by lyophilization, see Figure 1.

\subsection{Inductive plasma reactor}

The plasma oxidation and hydrogenation of $\mathrm{ZnO}$ NRs was done in a novel inductively coupled plasma (ICP) quartz reactor developed in the cooperation with SVCS Process Innovation, s.r.o. The reactor operates at 13.56 $\mathrm{MHz}, 10-200 \mathrm{~W}$ discharge power, pressure 1$100 \mathrm{~Pa}$ and gas flow 1-100 sccm: hydrogen (purity $99.999 \%$ ), oxygen (purity $99.995 \%$ ), argon (purity $99.998 \%$ ) and nitrogen (purity $99.999 \%)$. Prior the plasma treatment, the chamber was evacuated below $1 \mathrm{~Pa}$ and flushed by process gas to reduce residual gas contamination. To achieve good homogeneity, the powder was stirred during the plasma treatment using motorized cradle-like rotary quartz holder controlled by Arduino

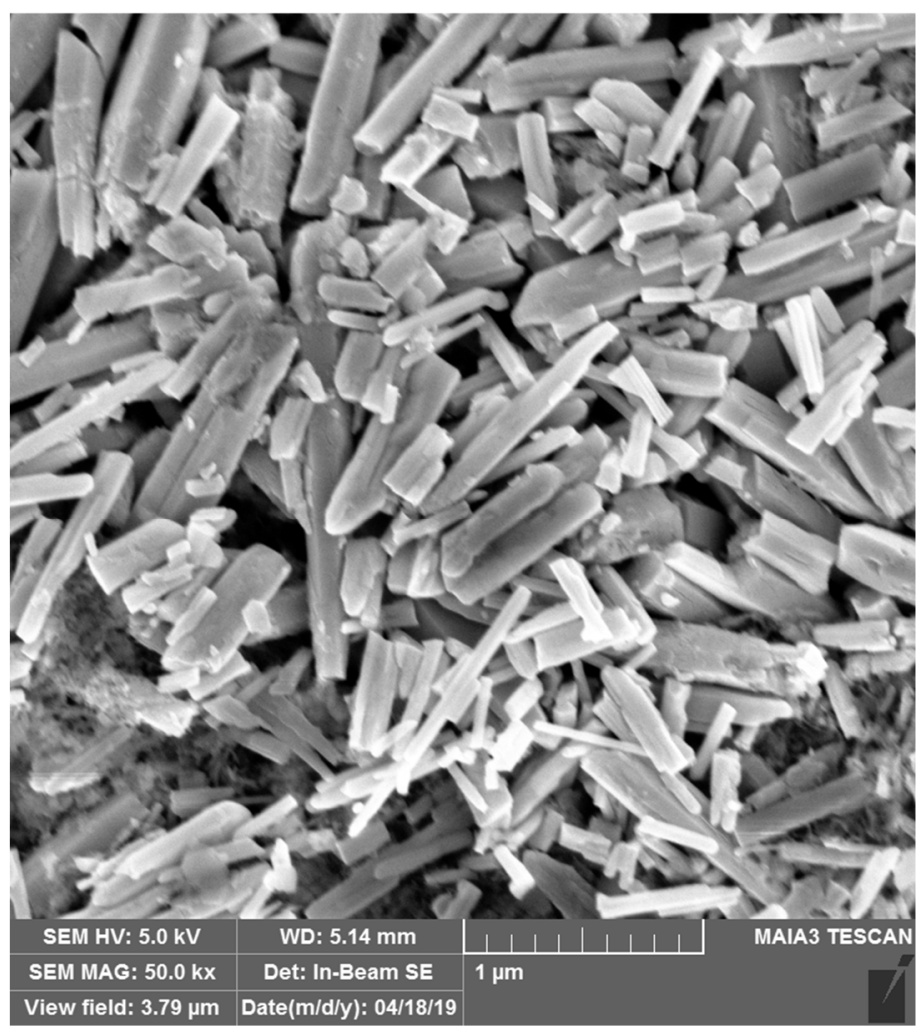

Figure 1 SEM image of ZnO NRs by MAIA3, TESCAN with the In-beam SE detector placed in objective lens.

The electron beam had an energy $5 \mathrm{keV}$.

microcontroller, see Figure 2. Prior the material characterization, the $\mathrm{ZnO}$ powder was sintered at room temperature to compact $0.5 \mathrm{~mm}$ thick pellets with diameter $3 \mathrm{~mm}$.

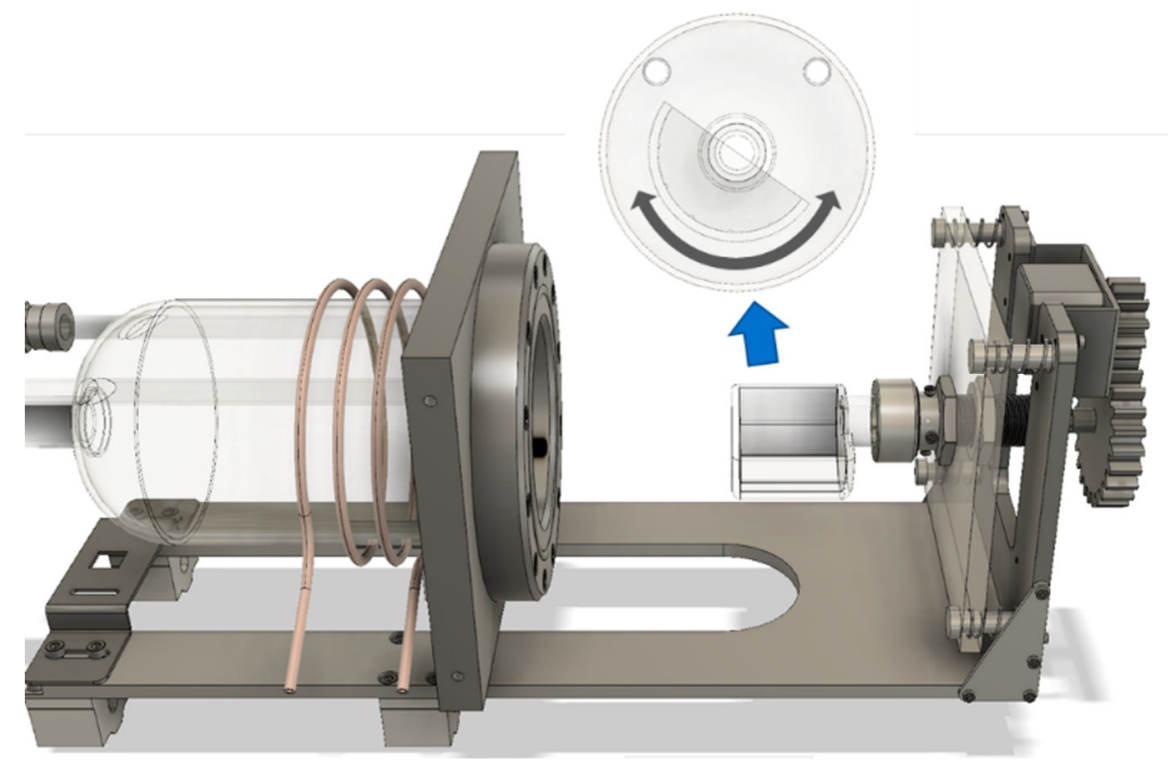

Figure 2 Rotary holder for ICP reactor swinging \pm 60 degrees to achieve good homogeneity of plasma treatment 


\subsection{Photoluminescence spectroscopy}

The schema of photoluminescence spectrometer is shown in Figure 3. The photo-excitation is provided by the fiber-coupled pulsed UV LED (Thorlabs \#M340F3) optically filtered by narrow band pass optical filter featuring $90 \%$ transmission at $340 \mathrm{~nm}$ and blocking wavelengths in the spectral range $250-310 \mathrm{~nm}$ and $370-450 \mathrm{~nm}$ by more than 10 orders and in $450-750 \mathrm{~nm}$ by 6 orders (EdmundOptics fluorescence filter \#84-092). The sample holder is positioned by two perpendicularly oriented translation stages manually driven by adjuster screws for precision motion. The emitted and scattered light is collected and focused onto the monochromator input slit by two $90^{\circ}$ off-axis mirrors coated by UV enhanced aluminum. The scattered UV light is filtered at the monochromator input slit by the fluorescence long pass filter EdmundOptics \#34-302 (UV grade fused silica substrate, the cut-on wavelength $375 \mathrm{~nm}$ ). The $\mathrm{f} / 4$ double gratings monochromator SPEX 1672 operating in the spectral range $300-900 \mathrm{~nm}$ is equipped with 1200 grooves $/ \mathrm{mm}$ gratings blazed at $500 \mathrm{~nm}$ with less than $10^{-9}$ scattered light. The spectral resolution is $2 \mathrm{~nm}$ with $1 \mathrm{~mm}$ slits. The monochromatic light intensity is detected at the monochromator output slit by the Peltier cooled multi-dynode multi-alkali red sensitive photomultiplier (Photonis XP2203B, the spectral range $300-700 \mathrm{~nm}$ ) biased to a high voltage by the Stanford Research Systems PS325/2500V-25W high voltage power supply. The photomultiplier current output is connected via coaxial cable to Stanford Research Systems SR570 low-noise current preamplifier followed by the Signal Recovery 5105 lock-in amplifier referenced to LED frequency.

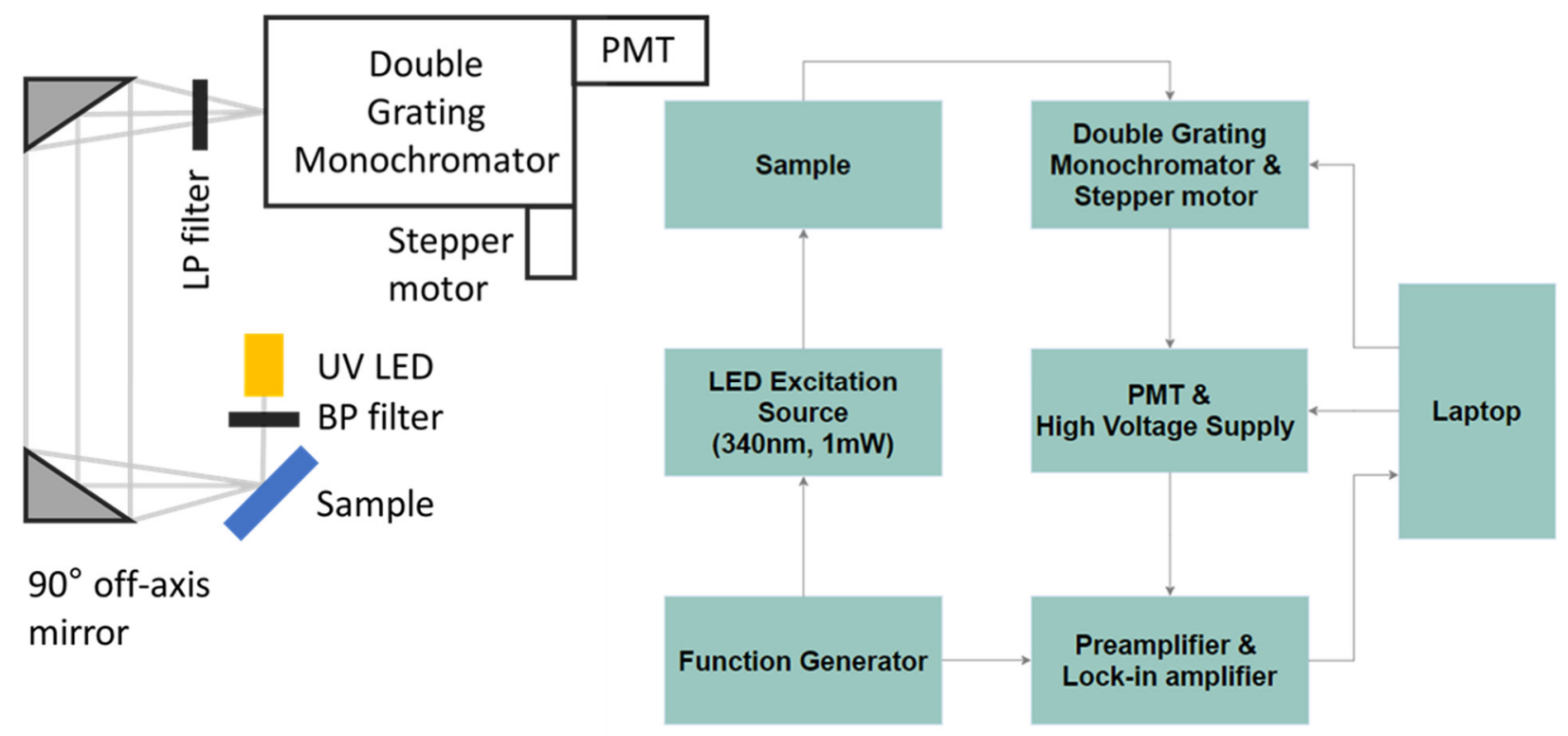

Figure 3 The schema of photoluminescence spectrometer with pulsed UV LED as a light source, band pass

(BP) and long pass (LP) filters, focusing off-axis mirrors, double grating monochromator SPEX 1672 controlled by a stepper motor and a photomultiplier (PMT)

\section{RESULTS AND DISCUSSION}

Figure 4 compares PL spectra of as grown ZnO NRs powder with PL spectra of ZnO NRs after plasma oxidation or hydrogenation. The excitation UV LED was operating at the wavelength $340 \mathrm{~nm}$ in pulse mode with the repetition rate $600 \mathrm{~Hz}$ and $50 \%$ duty cycle. The PL emission spectra were measured in the spectral range $370-670 \mathrm{~nm}$. The photomultiplier was biased by the cathode voltage $-1600 \mathrm{~V}$. The anode dark dc current as measured by pico-ammeter decreased from $2.8 \mathrm{nA}$ at $20^{\circ} \mathrm{C}$ to $0.2 \mathrm{nA}$ at $-15^{\circ} \mathrm{C}$ while the dc noise was reduced from $300 \mathrm{pA}$ to $50 \mathrm{pA}$. Since the ac current preamplifier gain was fixed to $10 \mu \mathrm{A} / \mathrm{V}$ and the input 
voltage range of lock-in amplifier is $1 \mu \mathrm{V}-1 \mathrm{~V}$, the maximum measurable ac photocurrent was $10 \mu \mathrm{A}$ and the minimum measurable ac photocurrent as well as the ac noise level was $10 \mathrm{pA}$ providing the dynamic range of 6 orders of magnitude. We have chosen the arbitrary units of PL intensity in such a way that 1 a.u. corresponds to $10 \mathrm{pA}$ photocurrent.

The as grown $\mathrm{ZnO}$ NRs pellets show measurable PL, but excitation peaks in near UV at $380 \mathrm{~nm}$ have lower intensity then the defect-related yellow PL (broad band $550-600 \mathrm{~nm}$ ). The oxygen plasma treatment has no effect on the observed PL emission spectra. However, the PL emission in near UV region has been significantly enhanced after ICP plasma hydrogenation whereas the deep defect related yellow PL (broad band 550 $600 \mathrm{~nm}$ ) has been significantly decreased. We explain the observed phenomena by passivation of defects at grain boundaries that significantly prolongs the lifetime of excitons.
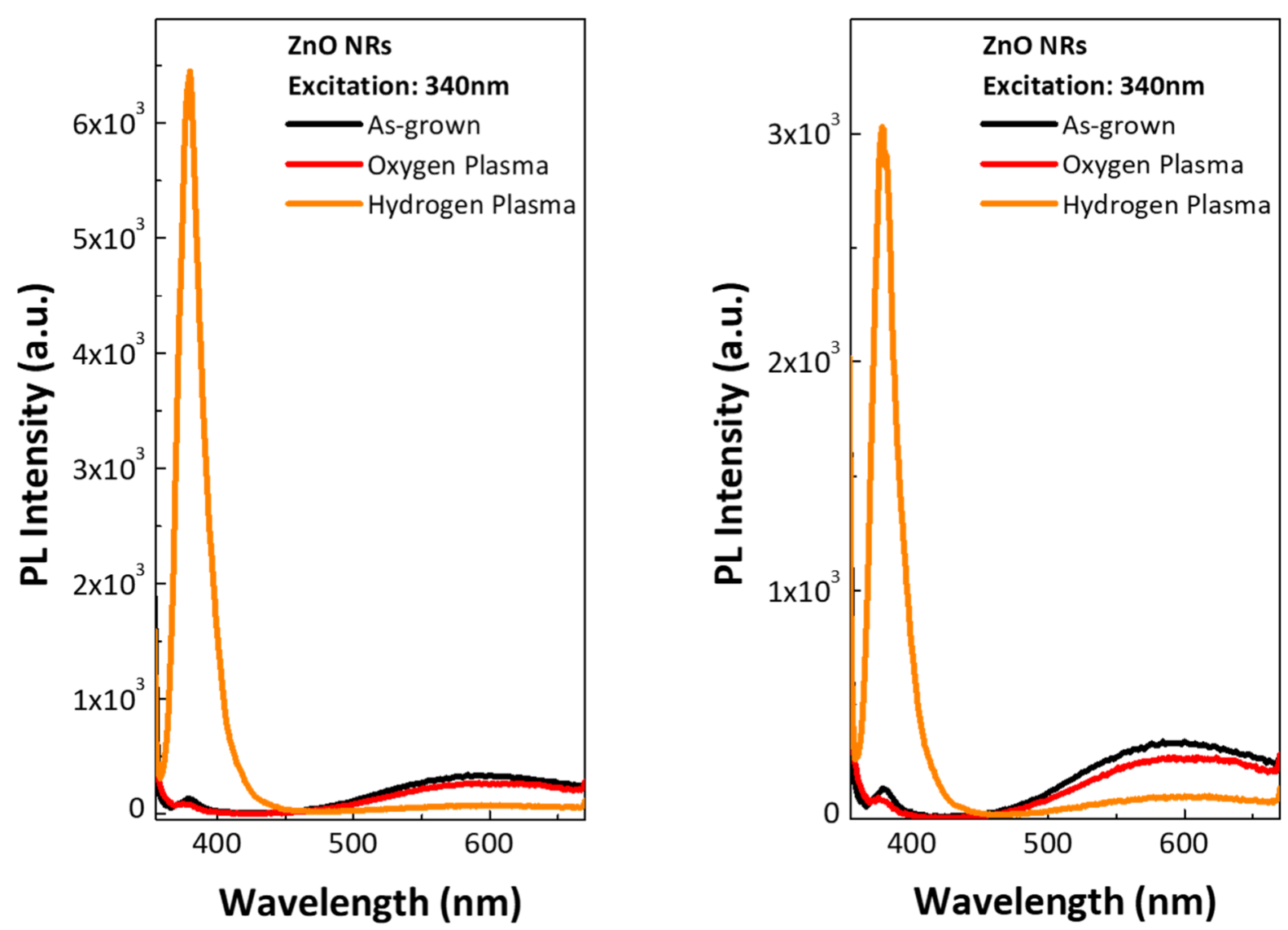

Figure 4 The photoluminescence emission spectra of two pellets prepared independently from ZnO NRs before (as-grown) and after exposition to oxygen or hydrogen plasma in ICP reactor. The excitation wavelength was $340 \mathrm{~nm}$.

\section{CONCLUSIONS}

We have developed an inexpensive and efficient the technology of hydrothermal growth of ZnO NRs powder from zinc nitrate hexahydrate $\left(\mathrm{Zn}\left(\mathrm{NO}_{3}\right)_{2} \cdot 6 \mathrm{H}_{2} \mathrm{O}\right)$ and hexamethylenetetramine $(\mathrm{HMTA})\left(\mathrm{C}_{6} \mathrm{H}_{12} \mathrm{~N}_{4}\right)$. The plasma oxidation and hydrogenation were done in a novel inductively coupled plasma (ICP) quartz reactor equipped with the rotary sample holder to stir powder during plasma treatment. We have shown that the photoluminescence drastically changes upon the exposure to hydrogen plasma treatments. 


\section{ACKNOWLEDGEMENTS}

This work was supported by the Czech Science Foundation project 19-02858J, The Technology Agency of the Czech Republic project GAMA TG02010056 (sub-project 08) and by the Operational Programme Research, Development and Education project SOLID21 -

CZ.02.1.01/0.0/0.0/16_019/0000760. Special thanks to Ing. Rayisa Yatskiv from the Institute of Physics of the Czech Academy of Sciences for SEM.

\section{REFERENCES}

[1] HSIEH, Ya-Ping, CHEN, Hsin-Yi, LIN, Ming-Zhang, SHIU, Shu-Chia, HOFMANN, Mario, CHERN, Ming-Yau, JIA, Xiaoting, YANG, Ying-Jay, CHANG, Hsiu-Ju, HUANG, Hsuan-Ming, TSENG, Shao-Chin, CHEN, Li-Chyong, CHEN, Kuei-Hsien, LIN, Ching-Fuh, LIANG, Chi-Te and CHEN, Yang-Fang. Electroluminescence from ZnO/SiNanotips Light-Emitting Diodes. Nano Letters. 2009. vol. 9, no. 5, pp. 1839-1843. Available from: https://doi.org/10.1021/nl803804a.

[2] YU, Guihua, XIE, Xing, PAN, Lijia, BAO, Zhenan and CUI, Yi. Hybrid nanostructured materials for highperformance electrochemical capacitors. Nano Energy. 2013. vol. 2, no. 2, pp. 213-234. Available from: https://doi.org/10.1016/j.nanoen.2012.10.006.

[3] TERESHCHENKO, Alla, BECHELANY, Mikhael, VITER, Roman, KHRANOVSKYY, Volodymyr, SMYNTYNA, Valentyn, STARODUB, Nikolay and YAKIMOVA, Rositza. Optical biosensors based on ZnO nanostructures: advantages and perspectives. A review. Sensors and Actuators B: Chemical. 2016. vol. 229, pp. 664-677. Available from: https://doi.org/10.1016/j.snb.2016.01.099.

[4] DAVYDOVA, Marina, LAPOSA, Alexandr, SMARHAK, Jiri, KROMKA, Alexander, NEYKOVA, Neda, NAHLIK, Josef, KROUTIL, Jiri, DRAHOKOUPIL, Jan and VOVES, Jan. Gas-sensing behaviour of ZnO/diamond nanostructures. Beilstein Journal of Nanotechnology. 2018. vol. 9, pp. 22-29. Available from: https://doi.org/10.3762/bjnano.9.4.

[5] PROCHÁZKOVÁ, Lenka, GBUR, Tomáš, ČUBA, Václav, JARÝ, Vítězslav and NIKL, Martin. Fabrication of highly efficient ZnO nanoscintillators. Optical Materials. 2015. vol. 47, pp. 67-71. Available from:

https://doi.org/10.1016/j.optmat.2015.07.001.

[6] NEYKOVA, Neda, STUCHLIK, Jiri, HRUSKA, Karel, PORUBA, Ales, REMES, Zdenek and POP-GEORGIEVSKI, Ognen. Study of the surface properties of $\mathrm{ZnO}$ nanocolumns used for thin-film solar cells. Beilstein Journal of Nanotechnology. 2017. vol. 8, pp. 446-451. Available from: https://doi.org/10.3762/bjnano.8.48.

[7] JANOTTI, Anderson and VAN DE WALLE, Chris G. Native point defects in ZnO. Physical Review B. 2007. vol. 76, no. 16. p. 165202. Available from: https://doi.org/10.1103/PhysRevB.76.165202.

[8] JANOTTI, Anderson and VAN DE WALLE, Chris G. Fundamentals of zinc oxide as a semiconductor. Reports on Progress in Physics. 2009. vol. 72, no. 12, p. 126501. Available from:

https://doi.org/10.1088/0034-4885/72/12/126501.

[9] NEYKOVA, Neda, CHANG, Yu-Ying, BURYI, Maksym, DAVYDOVA, Marina, KUCERKOVA, Romana, SIMEK, Daniel, REMES, Zdenek and POP-GEORGIEVSKI, Ognen. Study of ZnO nanorods grown under UV irradiation. Applied Surface Science. 2019. vol. 472, pp. 105-111. Available from: https://doi.org/10.1016/j.apsusc.2018.03.173.

[10] CHANG, Yu-Ying, STUCHLÍK, Jiří, NEYKOVA, Neda, SOUČEK, Josef and REMEŠ, Zdeněk. Optical properties of the plasma hydrogenated $\mathrm{ZnO}$ thin films. Journal of Electrical Engineering. 2017. vol. 68, no. 7, pp. 70-73. Available from: https://doi.org/10.1515/jee-2017-0060.

[11] MIČOVÁ, Júlia, BURYI, Maksym, ŠIMEK, Daniel, DRAHOKOUPIL, Jan, NEYKOVA, Neda, CHANG, Yu-Ying, REMEŠ, Zdeněk, POP-GEORGIEVSKI, Ognen, SVOBODA, Jan and IM, Chan. Synthesis of zinc oxide nanostructures and comparison of their crystal quality. Applied Surface Science. 2018. vol. 461, pp. 190-195. Available from: https://doi.org/10.1016/j.apsusc.2018.05.176. 